\title{
Analysis on the Difficulties of Chinese Culture Going-out
}

\author{
Jingping Yang \\ College of Humanities and Social Sciences, Heilongjiang Bayi Agricultural \\ University, Daqing, 163319, China \\ wendy5432@163.com
}

\begin{abstract}
Based on the analysis of the successful cases and the problems existing in Chinese cultural going-out strategy, the author tries to explain the detailed reasons on the difficulties of Chinese culture going-out, such as the lack of unique culture element, the quality of the work translation, to arouse Chinese people's attention of cultural confidence and the effort to spread the culture abroad in order to enhance the influence of Chinese culture abroad.
\end{abstract}

KEYWORDS: Chinese Culture, going-out, international reason, reading model

\section{Introduction}

Culture, as the spiritual wealth created by the people of a country in the long course of history, reflects the spirit and character of the country and its people. However, as China has long been on the "fringe" of the world's mainstream political and economic order, the people of western countries know little about Chinese culture, let alone understand and support the path of socialism with Chinese characteristics that the Chinese people are taking. Pan Wei, a professor of international politics at Peking University, believes that after more than 100 years, the Chinese people have emerged from beatings, starvation and cold to a period of abuse. In this period, the problem for China is that the influence, competitiveness and even contribution of Chinese culture in the world are not in line with China's international status and the rich cultural resources accumulated by China's 5,000 years of civilization. Compared with the influence of economy, the current Chinese culture has not enough internal cohesion, not strong external influence, and not enough competitiveness in the competition among various cultures. It has not formed its own favorable discourse power, and its voice is weak in international academia and the influence is so weak.

In terms of cultural trade, the United States accounts for $43 \%$ of the world's cultural market, the European Union for 34\%, and the Asia-pacific region for $19 \%$. Japan accounts for $10 \%$ of the region, South Korea for $5 \%$ and China and other 
Asia-pacific countries for just $4 \%$. China's culture trade only accounts a small portion and its influence is so little.

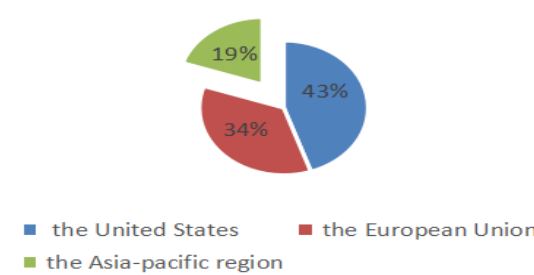

Figure 1 Percentage in Culture Trade

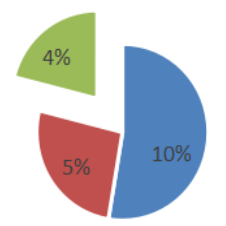

- Japan — South Korea — China and other Asia-pacific countries

Figure 2 Percentage in Asia-Pacific Region

Compared with the external economic surplus, the foreign exchange and dissemination of Chinese culture has a serious deficit. Not only is the number of cultural transmission insufficient, but also in the limited foreign cultural performance, those can reflect thousands of years of cultural accumulation and the real spirit of the Chinese nation literary and artistic works are very scarce.

\section{The Difficulties Encountered by Chinese Culture Going-out}

Chinese culture has begun to "go out", but what is the value of Chinese culture going out? How much influence does Chinese culture have on values and social life in the world today? Every year, the UN report on cultural development publishes 100 individuals and 100 books that have influenced the course of world history. In the early years, we had Confucius and the Analects, but in recent years, they have not appeared again. This shows that the quality of our cultural output is not high. The domestic cultural industry is booming, and the international media hardware has made significant progress. For example, China is now taking active measures to cover the global media, including the acquisition of some overseas TV stations by some Chinese media and enterprises. Therefore, in terms of the trend, China's media hardware construction is not a problem, but we do not have enough attractive cultural content, the media has no authority. In addition, in recent years, the development of Chinese website develops also very fast.

The contradiction between the vigorous industrialization and the weakened cultural construction is increasingly obvious. The state should pay more attention to the quality of the production and dissemination of cultural products. In terms of the current publishing industry, problems such as the decline in book quality and the decline in spiritual aesthetics are common. Taking a holistic view of China's "shortcomings" in the current international cultural exchange practice, we lack the micro practice of starting from details and using specific and vivid stories to highlight the power of Chinese culture. Although China is a major cultural producer in the world, its cultural transmission power and influence are obviously not strong. Compared with the great influence of western literary works in China, the influence 
of contemporary Chinese literature in the world is quite limited. Culture going-out should focus on copyright export and high value-added content products, which are the core of culture going-out.

\section{The Reasons Caused the Difficulties of Chinese Culture Going-out}

At present, creativity and creation in the forefront of China's cultural globalization are still weak links. Without good ideas, good stories, good images and original brands, the culture will not be competitive if it goes abroad. In the east and west culture, society, customs and other aspects of the great differences, there must be in the content, aesthetic requirements, ideological space excellent new cultural products appear. Some people regard the promotion of cultural soft power as the development of cultural industry. The cultural industry is important, but it is a necessary condition, not a sufficient one. The lack of cultural works of masters, the lack of original works, the low quality of cultural products and the lack of attraction of cultural contents are the core problems.

\subsection{The Lack of Chinese Unique Culture Elements}

With the great influence of globalization, lots of Chinese works focus more on international. Chinese culture as the unique works from Chinese, they should contain the unique characteristics and to spread traditional Chinese culture to the world, let the world know much more about the real China. Foreigners pay attention to China not only because they want to know about the past history and civilization, but also because they want to know about the concepts, mentality, thoughts, feelings and way of life of the contemporary Chinese people. Since modern times, in a market economy under the historical background and cultural secularization and industrialization, China's original ideology, values and the social value of political philosophy and other cultural forms are facing challenges, the impact of cultural diversity and traditional culture to some extent also makes the contemporary Chinese culture of morality, value confusion and the lack of cultural spirit of the crisis. In fact, the deep institutional culture and spiritual and cultural creativity of contemporary China's economic, political and social development and progress, especially Chinese wisdom and cultural innovation in promoting scientific and technological progress and resolving the dilemma of human development, are well worth summarizing and refining. Because in the fierce competition in today's world, the real influential cultural soft power is reflected in the current system of a country's values, science and technology, and society in various fields of innovation ability and deal with major issues and human voice and the theory of value influence on world affairs, to some extent, that is, the value of a nation's ideological influence.

Over thousands of years of history, China has contributed many unique ideas and important inventions to the world. Earth has promoted the civilized development of human society. It is only in modern times that the Chinese have made fewer and fewer ideological, institutional and technological innovations of world historical significance. The weakening of the originality of Chinese culture has greatly 
reduced the influence of Chinese civilization in the world. Even in the history of Chinese ideology and culture, China has a large can be proud of for the world cultural development has made important contributions to the classical thinkers, culture and people, culture, and contemporary cultural advantage is very weak, in leading the world culture development trend, affect human concept changes and value choice, promote institutional innovation of the change of human society, factors seem to be very weak in China.

At present, we have a complete system and organization for the external communication of ideology, but we have not mastered the defense strategy of ideology, so that we can not feel the wisdom and technical content in the external communication of ideology, let alone the cooperation and support from multiple channels. For a long time, the operation of ideology is mainly carried out in the political group, lacking the real participation of the academic community and the media group, usually one voice delivers one discourse, rather than multiple voices deliver the same discourse. In the construction of ideology, too much attention is paid to the form, while the content is not concise and permeable enough. Mainly in pay attention to the organization and the form of construction of ideology, but in the ideological content of publicity while we emphasize to highlight the theme, but actually didn't really do real, sometimes too simple, the lack of depth on the internal logic and continuity, often by storm, floating on the surface, relative to the form of solid, the content is empty. Therefore, it is necessary to strengthen the study of ideological content, vigorously strengthen the construction of socialist core value system, concentrate on the summary of contemporary spirit, and make efforts to win the hearts and minds of people and gain recognition for the contents of culture going out.

\subsection{Works are not so good enough to go out}

It seems that we are living in a fast paced society and people pay much more attention to the speed of everything. Whether you can output enough quantities to show your ability to some extent dominate the people's mind a lot. For some of the authors, the same situation. They want to write more works in a fixed period of time so it is quete easy to understand why the works are not so good, because it lacks the process to settle down and focus more on the spirit of the works itself. Even though we do have the successful cases of Chinese culture, it accounts for a small amount. For most of the contemporary Chinese literature, they are so difficult to go out, and this is the reason which is really important. For ancient Chinese culture, it does have a long history and it is quite well-know till now. We have set up lots of Confucius colleges abroad and foreigners are quite interested in ancient Chinese cultures. We used output of Beijing Opera, acrobatics, martial arts, shadow play, jasmine, dancing lions, lantern festival, folk paper-cut, material level, on the function of symbol to sketch the face of the "Chinese culture" in the western world, cater to the western aesthetic expectation, but as the mother carrier of the Chinese national spirit, as the root of the identity of the Chinese, the essence of Chinese traditional culture and wisdom has not been fully displayed. The main reason is the lack of enough 
attention to the inheritance of traditional culture for a long time, and the lack of understanding and respect for Chinese traditional culture, but also affect the contemporary Chinese cultural cohesion and cultural image. Even modern core values and contemporary cultural spirit are inseparable from the soil of traditional culture and the inheritance of core values. Contemporary Chinese traditional culture should be established on the basis of contemporary Chinese people's selfconsciousness and confidence in their own national culture. In addition, the approaches and methods of traditional culture going out also lack systematic overall planning and guidance. This fragmented phenomenon of culture going out makes the western world lack a comprehensive and in-depth understanding of Chinese traditional culture.

In the long historical process, the core value idea of Chinese traditional culture, embodies the Chinese nation for the value of life, the understanding and experience of life and life attitude, based on the traditional social life world and the life experience of the Chinese people, as for thousands of years people understand the world, to understand the intrinsic according to the history, comprehends the life. Even in the global economic integration, political landscape diversity, cultural diversity and high and new science and technology rapid development today, some from China traditional culture through thousands of years, would be, ascend, heritage values, still have to enhance national cohesion, rouse national spirit, and integrate the important role of social forces, coordinate benefit contradiction. These values are rooted in the cultural and psychological structure of the Chinese people, meet the needs of social development, have a universal significance beyond time and space, and are the precious spiritual wealth of the Chinese nation and the important spiritual support for modernization. Inadequate exploitation of traditional cultural resources is one of the main reasons for the low quality of Chinese culture going global.

\subsection{The Lack of International Vision}

From the current practice of cultural going-out, there is a certain gap in the demand of the international market for Chinese cultural works going global, whether in program content or production level, whether in historical themes or realistic themes reflecting China's reform and opening up. It is mainly reflected in the lack of international vision, lack of pertinence and lack of intercultural communication awareness in the content of China's cultural going out. Although different countries in such aspects as history, culture, religion has a bigger difference, but there are also the basic value of the mutual recognition, such as human rights protection, legal system construction, against terrorism, such as China, however, at present very few people have put forward to address the concerns of human civilization, rarely concern all over the world, also can become the center of the world talk about the problem.

In addition, the neglect or wrong understanding of the cultural difference between the recipient and China will also lead to the lack of attraction and affinity for the audience. Cultural content has poor pertinence and adaptability, and 
sometimes causes them to have comprehension obstacles or even ideological aversion and conflict, which has a bad effect. Just like the conflicts and conflicts caused by cultural differences in the movie scratch. In addition, it is sometimes difficult for the international community to accurately and comprehensively understand China's ideas and views in language with Chinese characteristics, thus greatly reducing the effectiveness. For example, "peaceful rise”, China emphasizes peaceful development, while foreign countries focus on the threat posed by rising powers. Culture, therefore, go out and content delivery to pay special attention to strengthen the research on the international cultural market, strengthen the adaptability of international vision and cross-cultural communication, want to consider the culture of different country interest and habit, let the people of different cultural background also can accurately understand the content of go out, to enhance its attraction, improve the quality.

To cultivate the internationalized talents should be a nice way to solve this problem. To vigorously develop higher education as the goal, to achieve education and international standards, to develop national higher education with a global perspective, to implement the international model of talent training, improve the level of higher education, and finally achieve the goal of higher education internationalization. Strengthening international exchanges and cooperation is the basis for deepening reform and opening up and achieving long-term stable economic development. China's education should also follow this pattern, deepen reform, seek ways out in various directions and cultivate international talents in an all-round and multi-level way.

\subsection{Influenced by the New Technology and Reading Model}

Cultural products are not of high quality and low attraction. Another reason is that culture and science and technology are not integrated enough, and the development and application of new technologies are rather backward. Into the 1950s, especially since the 90s, new technology into the field of cultural communication, digital technology by computer program code, such as text, images, sound form of digital signal, with large capacity, high speed, no loss of form for storage and transmission, on the speed, quantity and quality on cultural communication has entered a new state. The new technology also promotes the development of cultural industrialization: film and television has formed a complete production system and become a new economic growth point in some countries. We must not be western developed countries to adapt to the development of cultural productive forces accelerates the process of development of cultural production, compared with the developed countries, China's cultural industry in junior high more cultural products and high-tech content, high added value of cultural products, the ability of applying modern scientific and technological achievements is poorer, culture in the development of science and technology level is still stay in traditional technology stage, a lot of cultural industry in the production process is used in the developed countries make production tools. 
From the perspective of the historical process of cultural exchanges between China and the west since modern times, the cultural exchanges and interactions between China and the west are obviously unbalanced. Basically, Chinese people learn from the west. Although this situation has a lot to do with China's backwardness and cultural conservatism since modern times, it is also undeniably related to our own cultural attitudes and cultural confidence. Abandoning the national culture and copying the foreign culture can only lead to the disappearance and weakening of the national culture, but can not really achieve the harmonious communication between Chinese and western culture. At present, China's cultural exchange with foreign countries lacks a sense of equal exchange from theoretical research to practice. Researchers only focus on instilling western values and life beliefs in Chinese people, but rarely introduce the essence of local culture to learners. Cultural aphasia and cultural misunderstanding also make the effect of Chinese culture going out not so good. The unitary cultural communication channel is also one of the important reasons for the imbalance of cultural communication.

\subsection{Translators and the Translations}

Going-out of the translated literature of is different from export commodities, which is a process from domestication to alienation. The slow process of gradual increase in heterogeneity cannot be rushed. (Hui Wang, 2006:64) It is not easy for any foreign literature to break through in the western English market.

Chinese literature is more difficult to be accepted by the west, so we must face up to the time difference of receiving environment and language difference. The time gap refers to the fact that western readers have not become interested and enthusiastic about Chinese culture and literature until recently, while western readers have been reading western literature for more than 100 years, and they are now reading Chinese literature which is quite different in writing style, sentence structure and the main idea and the spirit in it. At the same time, the translation level doesn't not keep the same as what Yan Fu and Lin Shu did before.The language gap means that Chinese people learn English and understand western culture better than westerners. It is easier to learn more about Chinese culture. (Tianchen Xie, 2013:4749) according to Goethe's translation literature. Chinese literature is still in the first stage of translation and introduction to foreign countries. Be new to new things. The understanding and acceptance of knowledge needs to be related to the existing knowledge structure. It is necessary to consider the aesthetic taste of ordinary readers when choosing the mode of translation and introduction, and to bring out the new ideas with their pleasure, so that they read less resistance, more agreement. (Hui Wang, 2006:66) If foreignization is adopted in the first stage and western readers are required to accept the "difference" of China, western readers generally cannot accept it. To ensure the acceptability of Chinese translated literature in the target language world, to help Chinese literature in the target language country. To survive and develop, the mode of going-out translation and introduction of Chinese literature can be adjusted appropriately and realized step by step. 


\subsection{Complex International Public Opinion Environment}

China, as a socialism country, who bears different discourse system, ideology and values with the developed country in the west. But the most important thing the author wants to point out is that the English culture predominates the mainstream of the international culture. "China threatens the world" is a popular negative symbol vision in western media, which creates a geopolitical picture of traditional great power contention for hegemony. In this vision, China is constructed as a "new type of superpower" similar to the former Soviet union, with symbols and scenarios of "rapid growth of economic and military strength", "continuous expansion of overseas power", "formation of a new type of alliance of nations", "seeking regional hegemony", and "frightening neighboring countries". Under such a broad vision, foreign media have constructed a symbol system of geopolitical game and hegemonic intention around Chinese culture spreading organization, such as Confucius institute. Liu Cheng and Anran (2014) found that the mainstream media in the UK had "selective misreading" of Confucius institutes, which was highlighted by "China threat theory" and "Chinese will replace English". (Li Kaisheng \& Dai Changjiang, 2011)

"Communist dictatorship" is the symbolic vision of the ideological struggle between the east and the west in the "cold war", and the core symbolic vision of the confrontation between the western bloc and the socialist bloc countries with the liberal ideology of the dual opposition of "democratic-dictatorship". This negative vision has been rooted in the western public opinion field for nearly a hundred years, and its influence has been extended till now.In this vision, China's ruling party is discredited as the "dictator" of "one-party dictatorship" and the "sworn enemy of liberal democracy”.

Chinese culture going-out needs the support of international public opinion, and the formation of a good international public opinion environment not only needs tangible achievements to win respect and win public praise, but also needs to compete for the right to speak and occupy the moral high ground. "In order to gain the positive influence of the international public opinion field, we must learn how to win the initiative in the public opinion contest. China's external publicity and rebuttal often lack the overall design, get bogged down in the details of the debate, and fall into the values and discourse system set by the other side, into a passive situation.” (Mei Wu \& Wenbo Zhu, 2017)

Therefore, in the face of severe international public opinion situation, China's external communication should have a systematic engineering-style and fine toplevel design, and carry out brand building and corresponding public opinion monitoring for major cultural going-out projects.We should use scientific methods to carefully carry out symbol design, establish a discourse system that integrates Chinese domestic and abroad, and strive to create positive overseas public opinion, to combine Chinese discourse symbols to construct a discourse system that can occupy the moral commanding position. 


\section{Conclusion}

Chinese culture going-out does encounter bottleneck now. Compared with the traditional Chinese culture, contemporary ones are really in a difficult situation. Culture involves many subjects, problems and aspects. Chinese culture, mass culture, cultural industry, cultural communication, cultural diplomacy, etc., which is a relatively complex issue, it is not easy to figure out at the same time. This paper just analyzes the difficulties of Chinese culture going-out and doesn't give out the useful suggestions for the strategies of Chinese culture going-out, which will be illustrated in another paper. But the key point is: when the people who may get involved in spreading Chinese culture abroad, or the authors or the translators, these analyzed difficult reasons may be a great help to their research or study or writings which they can bear in mind and achieve a great success. We do have successful movies, books, great culture stuff that influenced the world a lot.

It is believed that the content cognition and content construction of Chinese culture are the core and soul of the strategy of going out, that is, what to go out is a very critical part. Today's world is a colorful, complex and diverse one. There are inevitably various differences among countries, including differences in social system and ideology, as well as differences in size, strength and wealth. Therefore, in the process of Chinese culture going-out, only adhere to the five principles of peaceful coexistence, adhere to the "harmonious but different, seeking common ground while putting aside differences” culture mind, focus on promoting human progress and civilization, to transcend the differences in social system and ideology, to shape the new image of modern civilization in China, contributing to the prosperity of world culture and human civilization the wisdom of the Chinese culture.

\section{Acknowledgments}

This research was financially supported by a study on Translation Strategies of Beidahuang Cultural Tourism Text (Project No.HNK125B-14-11A) and Research on Internationalization of Foreign Language Talent Cultivation in Agricultural Colleges and Universities -- a Case Study of Heilongjiang Bayi Agricultural University (Project No. wy2016081-c)

\section{References}

[1] Adorno, T. \& Horkheimer, (2002) Dialectic of Enlightenment, Stanford University Press

[2] Goldblatt, H. (2009). Mo Yan's Novels are wearing me out: Nominating Statement for the 2009 Newman Prize. World Literature Today, 83(4), 28-29.

[3] Moore, S. (2012). Chinese fiction writer Mo Yan wins Nobel Prize in Literature. The Washington Post, pp. 1-2. 
[4] Mo, Y. (1993). Red Sorghum: A novel of China (H. Goldblatt Trans). New York: Viking Penguin. (Original work published 1987)

[5] Liu cheng, Anran News Schema under Ideology: the Selective Misinterpretation of Confucius Institutes by British Mainstream Media, Journalism and Communication, $6^{\text {th }}$ Issue, 2014.

[6] Li Kaisheng, Dai Changjiang, Evaluation of the Public Opinion Environment of Confucius Institutes in the United States, World Economy and Politics, $7^{\text {th }}$ Issue, 2011.

[7] Wennian, Pan. (2010) Research on Going-out of China's Publishing Industry $[\mathrm{M}]$.

[8] Wu Mei, Zhu Wenbo, The Dilemma of International Public Opinion that Chinese Culture Faces in Going-out--A Case Study of the 13-year Analysis of International Public Opinion of Confucius Institute, Economic Herald, 2017

[9] Xiaoying Bao,(2014) Studies on the Translation and Communication Model for Chinese Literature Going-out--With the Communication of Mo Yan's English Translations in America as an Example, Doctoral Dissertation 